\title{
Interviewing children for the purposes of research in primary care
}

\author{
Moya Morison, Jim Moir and Theo Kwansa School of Social and Health Sciences, University of Abertay, Dundee,
} UK

\begin{abstract}
Interviewing can provide unique opportunities for professionals to gain some understanding of the child's subjective experience, where other means of data collection are inappropriate and other sources of data are less valid. This article is concerned with the principles and practicalities of interviewing children for the purposes of health-related research. It draws on the knowledge gained from three decades of research involving interviewing young people in many contexts, including health care, social welfare and child protection. A conceptual framework is presented to illustrate the interactive and iterative processes that occur between interviewer and interviewee, and the pivotal importance of context in shaping any interaction. The influences of the young person's linguistic, cognitive and social skills are discussed. The effects of the gender and ethnicity of both the researcher and the researched are considered in relation to the conduct of the interview, and the influence of adult biases and perspectives on the evaluation and interpretation of data is explored.
\end{abstract}

Key words: children; interviewing; research methods

\section{Introduction}

Interviewing can provide unique opportunities for health care professionals and researchers to gain some understanding of the child's subjective experience, where other means of data collection, such as questionnaires, may be inappropriate because of the child's age or the sensitivity of the topic, and where other sources of data, such as parents and teachers, are less valid.

This article is concerned with the principles and practicalities of interviewing children for the purposes of health-related research. It is based on the personal experiences of the authors and a systematic review of a broad range of research literature, with different theoretical and associated methodological orientations, ranging from the ethnographic (Morison, 1996) to the more constructionist (Moir and Abraham, 1996). The focus is on the chal-

Address for correspondence: Dr Moya Morison, School of Social and Health Sciences, University of Abertay, Marketgait House, 158 Marketgait, Dundee DD1 1NJ, UK. Email: m.morison@tay.ac.uk

(C)Arnold 2000 lenges of interviewing pre-adolescent children, including those of pre-school age.

An examination of the literature has revealed that there is only a modest amount of empirically established knowledge, and many unresearched aspects (Kortesluoma and Hentinen, 1995; Faller and Everson, 1996), yet interviewing is one of the most commonly used approaches for gaining an understanding of the child's viewpoint, whether for the purposes of therapy (Kanfer et al., 1992; McConaughy, 1996), research (Graue and Walsh, 1998; Holmes, 1998) or testimony in a court of law (Saywitz and Goodman, 1996) (see Table 1).

In the past, children's thoughts and feelings have often been elicited second hand, from parents or guardians, and children have tended to be regarded as unreliable witnesses whose credibility can be challenged on the basis of a lack of linguistic skills, unreliable recall, susceptibility to suggestion and a tendency to confuse fantasy with reality (Moston, 1990; Dent, 1991; Lamb et al., 1994; Warren and McGough, 1996; Schetky, 1997). However, there is evidence that children can be reliable witnesses and that they can comment meaningfully about 1463-4236(2000)PC015OA 


\section{Moya Morison, Jim Moir and Theo Kwansa}

Table 1 Some reasons for interviewing children in primary care

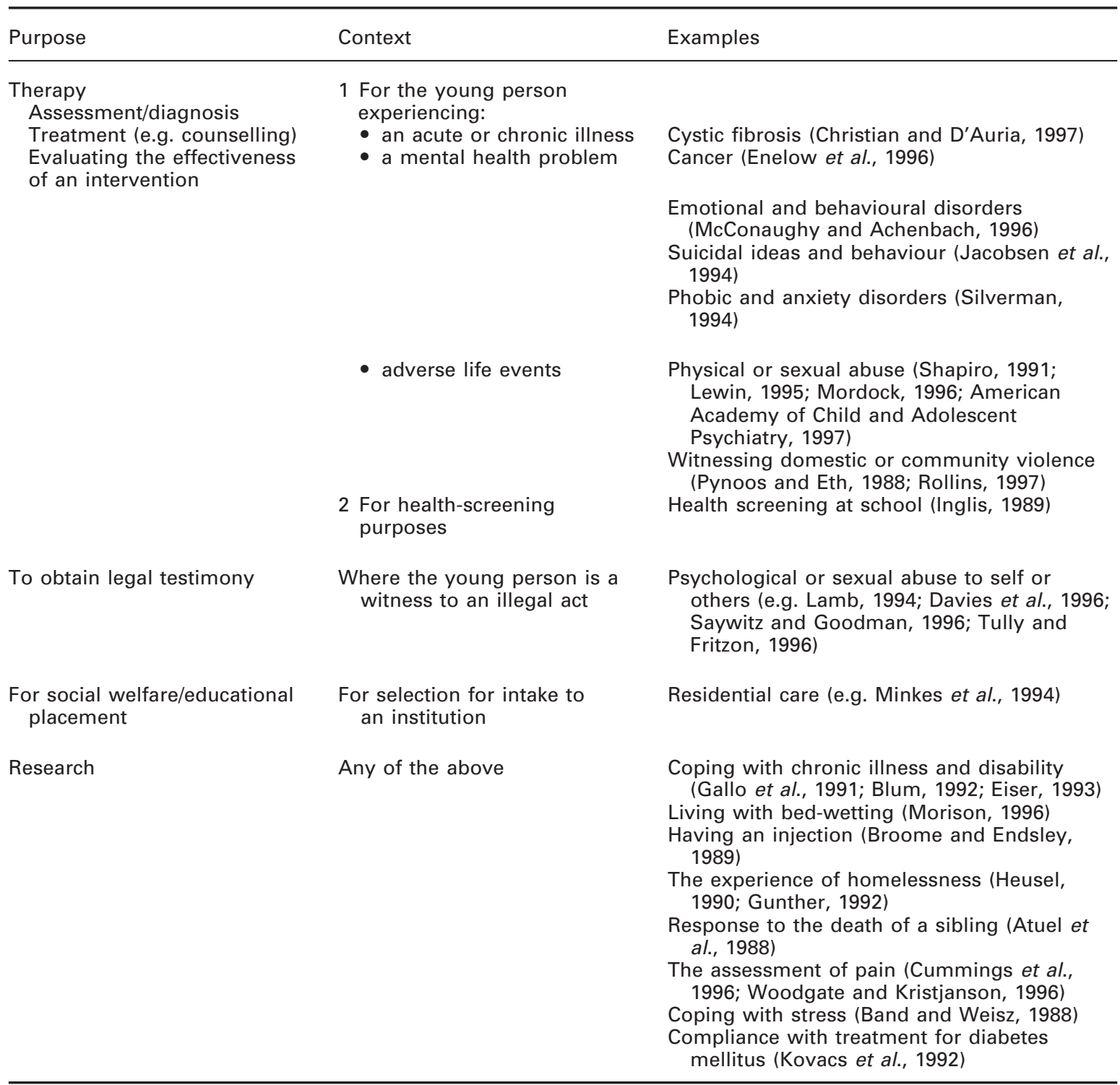

their thoughts, feelings and experiences when questioned appropriately (Amato and Ochiltree, 1987; Robinson, 1987; Faux et al., 1988; Oakley, 1994). Children can also be taught strategies to improve recall (Saywitz et al., 1996).

There is an increasing insistence that the feelings and wishes of young people should be taken into account prior to any therapeutic intervention, or before any change in social or welfare provision is made (Minkes et al., 1994). This policy is reflected in the UN Convention on the Rights of the Child, and in government policy, with its emphasis on maximizing user involvement in decision making (Department of Health, 1997, 1998, 1999a, b). Yet 
it is difficult to achieve a valid understanding of a child's wishes, because of the biases and expectations that adults bring to their evaluation of the situation. Similar concerns prevail in relation to the interpretation of data from young people who have been the subject of research (Graue and Walsh, 1998).

The influence on interpersonal communication of the age-related cognitive, linguistic and social development of young people is being increasingly understood (Steward et al., 1993; Goodwin, 1997). It is also recognized that the gender and ethnicity of the young person and of the researcher can compound problems of communication, understanding and interpretation of the child's world (Maccoby, 1990; Williams and Heikes, 1993; Beoku-Betts, 1994), and many complex ethical issues can arise in the process (Alderson, 1993, 1995; Scott-Jones, 1994; Wescott, 1994).

To explore and shed light on this complexity is the purpose of this paper, which includes advice for those less accustomed to communicating with children on how to translate research-based principles into practice.

\section{The interview process: a conceptual model}

A conceptual model illustrating the key components of the interview process is shown in Figure 1. It represents a synthesis of an extensive review of the literature. The search parameters used were interview* and child*. A total of 239 relevant papers were identified from PsycLIT, 46 papers from CINAHL, and 9 papers from the British Nursing Index (BNI).

The model assumes a process of mutual simultaneous shaping (Lincoln and Guba, 1985), which is the principle of interdependent components mutually and simultaneously influencing all other components, as the young person and the interviewer interact and attempt to make sense of each other's view of the world. Whether the interview is structured, semi-structured or unstructured, it is contended that the interviewer is never totally in control, inaccessible or unaffected by the actions and responses of the young person.

The concepts of interdependence and mutuality run counter to the attempts of interviewers in the 1950 s and 1960s to assume an objective stance:
Interviewing ... is a fairly straightforward job, not one calling for exceptional industry, charm or tact ... the interviewer's personality should be neither over-aggressive nor over-sociable. Pleasantness and a businesslike nature is the ideal combination.

(Moser, 1958: 195)

Reflecting on the methodological problems highlighted by her research on motherhood, Ann Oakley (1981) was among the first to demonstrate the impossibility of adopting a neutral stance, as well as questioning the prevailing notion that interviewing was a one-way process which involved eliciting information from 'respondents' without reciprocation or any form of personal disclosure. Despite the inherent power imbalance between children and researchers, many researchers who have worked with children highlight the potential for the child to set the agenda during exploratory, in-depth interactions (Mandell, 1988; Pellegrini, 1996).

The final principle to be explicated, before describing each of the components of the model in turn, is the concept of 'wholeness', which implies that no single component can be understood in isolation from the rest. Inherent in this concept is the idea (and, for the purposes of this paper, the caution) that the whole is more than the sum of the parts. This is congruent both with the naturalistic paradigm, which underpins a great deal of exploratory research with children, and with systems theory, which is a useful approach to understanding children in the context of their families and their wider social existence (Broderick, 1993; Rosenblatt, 1994).

\section{The importance of context}

The context of an interview can have a profound influence on the nature of the interaction and its outcome, including whether the child chooses to engage with the interviewer at all. Aspects of context (illustrated in Figure 1) include the nature of the topic under discussion, the purpose of the interview, and the physical and social environment in which the interview is to take place.

\section{The nature of the topic}

Before embarking on any interview it can be useful to reflect on the emotions that are likely to be elicited by the nature of the topic itself. There 


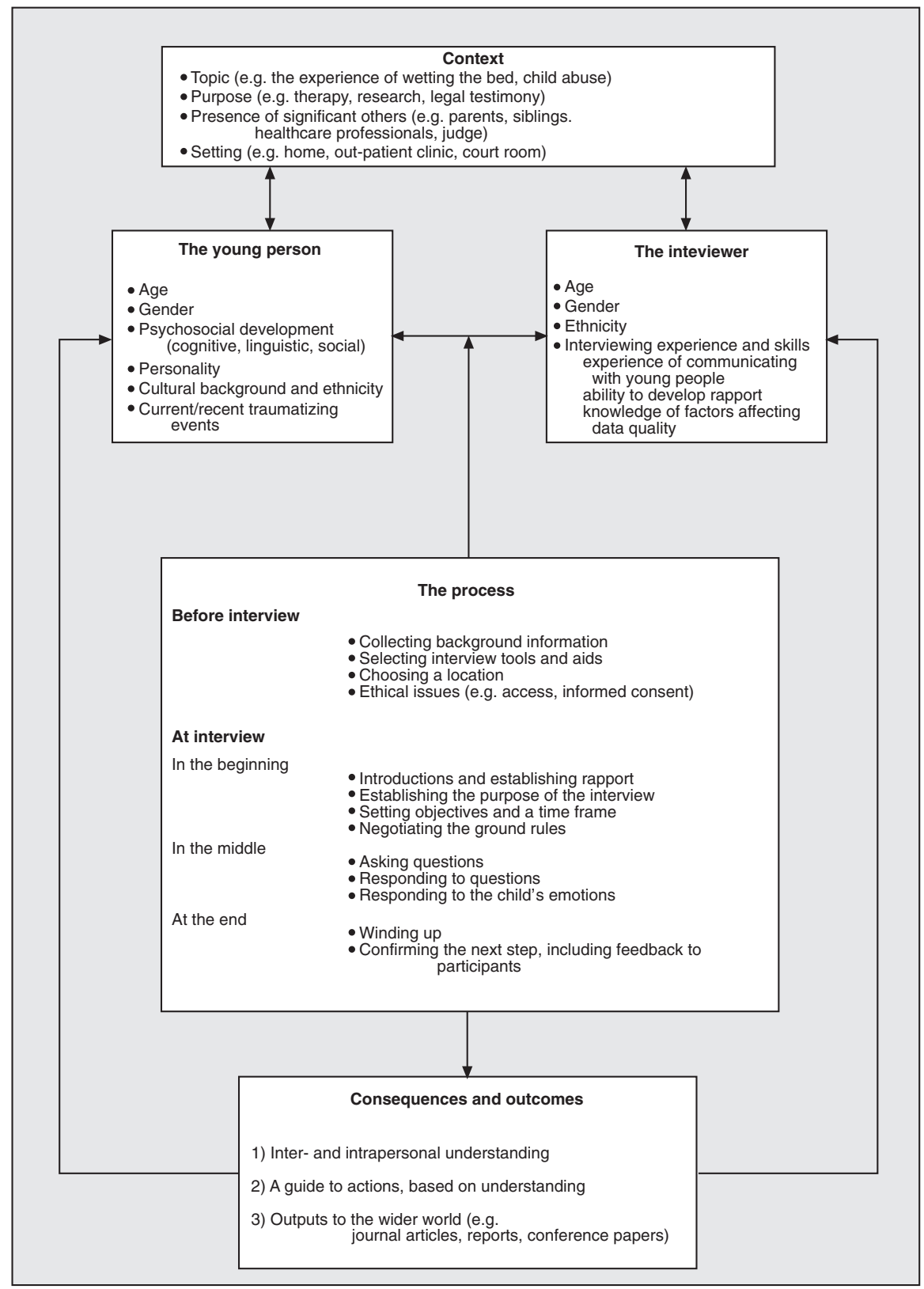

Figure 1 The interview process

are many health-related instances where children are likely to feel ashamed of their inability to achieve tasks that other children of their age can achieve easily. One such example is lack of night-time bladder control.
Many of the children in Morison's (1996) study of families' experiences of living with a young person who wet their bed felt embarrassed and ashamed. Their tendency was to hide the problem so as to avoid the humiliation of having their per-

Primary Health Care Research and Development 2000; 1: 113-130 
ceived failing observed by others, with the loss of self-esteem that this entailed. As a result, some young people failed to attend their first interview, even though this had been carefully negotiated with the family and was arranged to take place in the young person's own home. Avoidance behaviour was especially common in older children, particularly when it was anticipated that other family members might be present. One 12-year-old took the long way home from school on the afternoon of his interview, and was eventually found hiding behind the door. Another child disappeared for the evening when the interview had been arranged. This raises issues relating to informed consent for young people under the age of 18 years. These will be addressed later in this paper.

Although children may have willingly agreed to take part in a study, they may be economical with the truth, if they perceive full disclosure to be too humiliating:

John (aged 8 years): ... I never wet until Christmas - well, last year I wet once because I was too excited. That was why I wet at Christmas. I was too excited.

Moya (the researcher): Too excited. Any other times when it happens?

John: When it's my birthday.

According to his urinary symptoms diary, John was actually wetting the bed two or three nights a week.

Speaking from a clinician's perspective, Hughes and Baker (1990) strongly adjure that children's defence mechanisms should be respected, and they warn against any attempt to confront children with their use of denial outwith an ongoing therapeutic relationship. In relation to research this highlights another important ethical issue, namely nonmaleficence.

The purpose of the interview: perceived benefits and threats

Whether the context is therapy, the giving of legal testimony, or research, the willingness of the child to participate in an interview can reflect their perception of the possible personal benefit of participation, weighed against the perceived threat, including threats to self-esteem (see Figure 2).

When asked how he felt about taking part in the bed-wetting study, John (aged 8 years) replied:

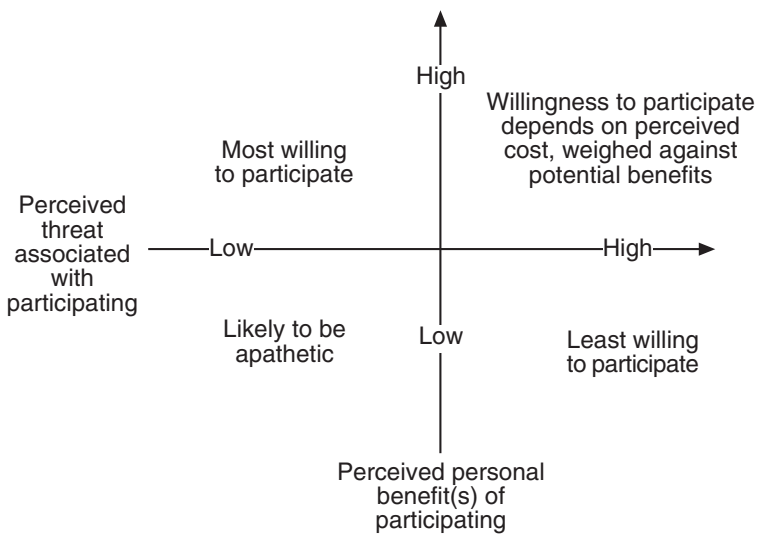

Figure 2 The influence of perceived personal benefit and perceived threat on the young person's willingness to be interviewed for the purposes of research

Happy ... it's the first time I've ever been in a project with adults and that, and I'm really happy ... I'm enjoying myself.

When asked what he had enjoyed most he replied:

Doing the faces and the pictures.

In this case, the self-esteem associated with being in an 'adult project' and the pleasurable nature of the child-focused activities overcame the young person's initial reluctance about self-disclosure.

In other circumstances, such as previous family violence or child abuse, children may be very fearful of the consequences of talking to a person who is perceived as being in authority, both for themselves and for the negative consequences for the family as a whole (Gunther, 1992).

\section{The presence and attitudes of significant others}

The presence and attitudes of other people who are significant to the young person can have a marked influence on the interview process, which may be either positive or negative. Even when families and children can perceive no personal benefit from participating in a study, they may nevertheless agree to take part because the parents suggest to the young person that their participation could help other people.

Supportive and empathetic parents can encourage openness on the part of the child by creating a safe environment for the disclosure of thoughts and feelings, as well as more factual information. 
Disapproving parents can have the opposite effect:

Mother of Tracy (aged 9 years): She just keeps things in, ken [you understand], she'll no communicate, ken - she'll just no sit and talk to you.

Tracy's mother had punished the child in many ways for wetting the bed. Tracy found it very difficult to communicate with the researcher until she was encouraged to draw pictures of herself in certain situations.

\section{The influence of the setting}

Many problems of shyness and embarrassment can be overcome by interviewing the child in the familiarity of their own home, or in other natural settings. However, this can lead to a number of problems for the interviewer. Lack of privacy can be a problem when the family have adopted an 'open-house' policy and other siblings, friends and their parents wander in and out at will. This is a particular hazard in the late afternoon (after school and before the children's tea-time), which is often chosen by the family as a convenient time for them to meet the researcher.

In his study of homeless children, Heusel (1990) describes interviewing children against the background noise of city traffic, in the corner of the living room or at a dining table in an overcrowded shelter while other children were playing nearby. Holmes (1998) describes similar problems with regard to finding quiet places in the school setting, where the probability of being disturbed is low.

Set against these practical difficulties there are many secondary benefits of interviewing children in their natural setting, including the ability to observe the nature of the young person's behaviour and interactions with others (Bronfenbrenner, 1986; Kazak, 1992).

In practice, a quiet environment can often be negotiated with the family. If this is not possible, it is advisable to use the highest-quality audio equipment that can be afforded, as this can result in a tape recording in which individuals can still be heard above the noise of dogs, babies, the television and passing traffic.

\section{What does the young person bring to the situation?}

A growing body of literature in the field of child development supports the notion that children per- ceive, conceptualize and reason about themselves, other people and everyday events in ways that are qualitatively different from those of adults (Mussen et al., 1996; Hetherington and Parke, 1998). Despite adult researchers' best efforts to adopt a 'least adult role' when studying children (Mandell, 1988), these differences can lead to misunderstandings and misinterpretations of the child's lived experience.

One uncommon solution to the problem is to use children as field assistants, as Gertrude Huntington has done in her anthropological studies (Huntington, 1987). One benefit that Huntington found was that her children could report to her on those activities from which adults were excluded. However, for the most part researchers are adults and need to acquire some understanding of children's development in relation to linguistic, cognitive and social skills, and to understand how children's motivations, goals and coping strategies change over time and can profoundly influence their conduct during an interview, including their ability and willingness to share their thoughts and feelings with the interviewer (Hughes and Baker, 1990). Some key research findings are summarized below, but it must be emphasized that children are individuals and will reach developmental milestones at different ages.

\section{Language development}

Language serves many purposes for the developing child, enabling them to express their needs and wishes, to interact pleasurably with others and to understand their physical and social environment. The acquisition of language is a complex developmental task that requires the development of skills in the domains of phonology, semantics, grammar and pragmatics. Clearly, a detailed discussion of the processes involved in acquiring these skills is beyond the scope of this paper. Instead, the aim is to alert the researcher to certain developmental milestones (see Table 2) and their implications for interviewing, especially with regard to asking questions.

Pre-school children Whereas adolescents and adults are able to respond to open-ended questions of the 'Tell me about...' type, which can prove very illuminating in qualitative research, such questions are likely to result in a blank look or at best a series of unrelated associations from 
Table 2 A brief overview of language development and skills acquisition in children up to the age of 6 years

\begin{tabular}{|c|c|}
\hline Age & Language characteristics and skills \\
\hline 1 year & $\begin{array}{l}\text { Utters first understandable words, but does not respond verbally when } \\
\text { spoken to in simple phrases }\end{array}$ \\
\hline 18 months & Uses two-word combinations \\
\hline 2 years & $\begin{array}{l}\text { Vocabulary now } 200-300 \text { words } \\
\text { Can initiate conversations and respond in simple phrases }\end{array}$ \\
\hline $3-4$ years & $\begin{array}{l}\text { Over } 1000 \text {-word vocabulary. Uses simple sentences } \\
\text { Understands 'who', 'what' and 'where' questions } \\
\text { Poor conceptualization of past tense and past events } \\
\text { Understands the social process of 'taking turns' in conversations }\end{array}$ \\
\hline $5-6$ years & $\begin{array}{l}2000 \text { to } 2500 \text {-word vocabulary. Communicates using longer and more } \\
\text { complex sentences } \\
\text { Good grasp of past tense. Can recall and describe past events } \\
\text { Understands 'when', 'why' and 'how' questions and can respond } \\
\text { appropriately }\end{array}$ \\
\hline
\end{tabular}

younger children (Hughes and Baker, 1990). Hutcheson et al. (1995) found that younger children frequently failed to answer general questions, but provided information relevant to those same questions later in the interview.

Pre-school children are still learning the pragmatics of social communication. They will normally have mastered the notion of 'taking turns' by the age of 3-4 years, although they may not always respond to every question put by the researcher.

Pre-school children appear to be especially vulnerable to the wording of questions (Greenstock and Pipe, 1996), to the persona of the interviewer and the type of information requested (Saywitz and Goodman, 1996). Influenced in part by shorter concentration spans and distractibility, young children can find it difficult to sustain conversation without frequent prompting and empathetic verbal and nonverbal responses. However, there is a danger of asking too many questions and of asking 'forcedchoice' questions, which can lead to single-word answers which may not be particularly illuminating.

Young children are often most expansive in situations where the researcher seeks to exercise minimal control over the interaction. Saywitz and Goodman (1996) suggest that 'professing confusion' is much more successful than coercion in encouraging pre-school children to elaborate on an answer or to disentangle apparent inconsistencies. Misunderstandings can be minimized by keeping questions short and using familiar vocabulary. With careful and sensitive questioning, the interviewing of pre-school children can yield rich multi-dimensional data, as illustrated, for example, by Robinson's (1987) study of children's perceptions of health and illness.

Much has been written about the use of anatomically correct dolls and models, especially in cases of suspected child abuse (Priestley and Pipe, 1997). However, De Loache (1995) sounds a note of caution with regard to very young children, who have difficulty in realizing that models such as dolls function both as an object and as a symbolic representation of an object, which is a prerequisite to reasoning. Colour photographs can be a useful aid to communication with children as young as 3 years old, as in Meyer's (1992) study of children's responses to nursing attire.

The school-age child Growth in social communication skills is most rapid in the pre-school years (see Table 2), but it continues throughout middle childhood.

In a study of the impact of certain questioning styles on the accuracy of children's testimony, Carter et al. (1996) found that children reported an event significantly less accurately when questioned with complex, developmentally inappropriate 
questions rather than simple questions, yet the children rarely admitted to comprehension failure. It may therefore sometimes be difficult for the researcher to be aware that a question has only been poorly understood, unless the child's response is clearly inappropriate. Another pitfall is to ask leading questions, which can result in distorted responses (Huon et al., 1997).

As Faux et al. (1988) have pointed out, unstructured or semi-structured data-collecting techniques facilitate young people in enunciating their point of view. The use of drawings, models and other visual aids to communication can overcome many of the linguistic difficulties associated with conversations involving more complex concepts or sensitive situations (Dahlquist, 1990; Priestley and Pipe, 1997). If the topic is less sensitive, it may be appropriate to encourage children to give written accounts. In a study of age and gender differences in children's Christmas requests, Almquist (1989) asked the older children (aged 10 years) to write letters to Santa Claus stating what they would like to receive. The 7-year-olds were allowed to dictate their letters.

\section{Cognitive development and social reasoning}

Children actively construe meaning from their experiences. Knowing how children organize their experiences and reason about them facilitates reliable interpretation of data from children.

Children's linguistic development, described above, mirrors their cognitive development (Hughes and Baker, 1990). Whether answering questions in an interview situation or completing a simple questionnaire, the accuracy of children's self-reports will depend on their acquisition of certain cognitive and social-cognitive skills, as well as their linguistic ability. One assumption that underpins the use of any self-report measures with children is that they do indeed have a coherent sense of 'self', for their reports to be meaningful (Stone and Lemanek, 1990). Other major developmental tasks for children include the conceptualization of others, and the cognitive understanding of emotions.

Visual self-recognition occurs before the age of 3 years, and it is during these early years (from about the age of 7 months) that the child comes to understand the meaning of certain facial expressions, and can communicate in relation to certain simple emotions, such as happiness.
A striking development that occurs at around the age of 4 years is the onset of autobiographical memory (Nelson, 1992). By 4 to 6 years of age children can describe themselves and others in concrete terms, such as physical appearance and simple actions. They can accurately and reliably differentiate between happiness and sadness, although pre-school children sometimes confuse sad and angry facial expressions. The reporting of feelings is usually situational, reflecting a description of the circumstances in which the feelings occur. This is exemplified by Martin (aged 6 years) when describing his feelings on finding his bed wet in the mornings:

I cry ... 'You've to keep it dry' [mother's admonition].

At this age, children's 'all or nothing' conceptualizations of their own personal traits, sometimes referred to as 'dichotomous thinking' (Hughes, 1989), can lead to over-generalization, especially with regard to negative traits.

Between the ages of 7 and 11 years, the young person's self-descriptions begin to include psychological characteristics and social comparisons, and their understanding of themselves is more situationally based. For example, an 8-year-old may consider himself to be 'lucky' in general, but 'unlucky' when it comes to learning how to become dry at night. During these middle school years the young person begins to differentiate between mental and physical aspects of self, and learns to differentiate between a variety of negative emotions, such as anger, fear, disgust and shame. Children in middle childhood can usually report meaningfully on their perceptions of other people. One aspect of person perception is that of social role, and one role of special importance to children is that of a friend. As children mature, they come to think of friendships in terms of enduring, mutually supportive relationships characterized by trust and intimacy (Hughes, 1989):

Moya (researcher): Do any of your friends know about it [the bed-wetting]?

Michelle (aged 8 years): One friend ... Cos, I know I can trust her. And she says, 'Right, I'll tell not one person'. She always tells me the truth ... she says 'You have to stop it, everybody will find out sooner or later.' 
According to Mussen et al. (1990), pre-school children almost always say that they are satisfied and happy with themselves, while at the same time looking somewhat mystified by questions relating to self-image and self-esteem. They suggest that children have a more clearly formulated sense of self-worth and competence by the age of 9 or 10 years, but from this age they may not want to admit to themselves or to others that they have undesirable qualities, and they may report more positive self-esteem than they really feel. Understanding these differences is important when attempting to interpret self-report data from young people of different ages. It is also important when visual techniques, such as Andrews' and Withey's (1976) Delighted-Terrible Faces Scale, are used to explore children's feelings in certain situations.

The ability to describe themselves in more abstract, complex terms and to understand the possibility of a discrepancy between inner feelings and outward behaviour does not normally occur until early adolescence, by which time young people are beginning to develop personal theories both to account for what happens to them, and to account for the behaviour of others.

From the above brief description it can be seen that children's understanding of themselves and others shifts from a focus on concrete, observable characteristics to an understanding of more abstract, psychological constructs, and an ability to appraise the influence of situational and dispositional factors, which enables young people to come to an understanding of themselves and make inferences about the feelings and likely behaviour of others. A more detailed exposition of cognitive development can be found in Hetherington and Parke (1998) and Mussen et al. (1996).

\section{Cultural background and ethnicity}

The nature of 'childhood' varies according to socio-cultural background. For example, western conceptions of the self in terms of 'possessive individualism' - that is, the view that we 'own' ourselves in terms of motivated action - are not shared by other cultures, which take a more collectivist view of identity (Macpherson, 1962; Shotter, 1985, 1989; Wetherell and Maybin, 1996). It is also the case that a child's cognitive abilities do not map on to their age irrespective of cultural background. This view presupposes an 'age-and-stage model' of 'natural' maturation, and has been challenged by theorists who have taken a more socio-cultural viewpoint (Vygotsky, 1962; Bruner, 1985).

The 'rules' for adult-child interaction are culturally defined, as are the 'rules' for the expression of experiences and emotions. For example, terms such as 'happiness', 'sadness' or 'anger' are bound up with particular ways of speaking about events and relationships which may not be directly comparable in cross-cultural terms (Wetherell and Maybin, 1996). Such 'experiences' are embedded in particular cultural stories, and may not be so easy to share within an interview setting. It is for these reasons that the ethnic and cultural background of the child being interviewed must be taken into account throughout the research process.

\section{What does the interviewer bring to the situation?}

An interviewer's questions provide the part of the contextual framework for the construction of a child's responses. Answers are shaped for a particular audience in response to a particular question. Some researchers identify the problem of 'interviewer bias' and require that questions should not be leading and respondents should be encouraged to provide in-depth answers, with the interviewer interspersing a few innocuous prompts to encourage the respondent to continue. This approach presupposes that the researcher is a neutral soundingboard (Moser, 1958), a concept that was refuted as long ago as 1981 by Ann Oakley.

An alternative perspective is to treat the situated nature of the interview as an item for analytical concern. Thus issues of interviewer power, ethnicity and gender become part of the analysis process rather than being methodological problems.

Interviewer influences are acknowledged as being ever present, and in the case of interviewing children, they include such features as prior contact or privileged access through parents or professionals such as teachers or doctors, ethnic or gender similarity or difference, and the age of the interviewer (Banister et al., 1994; Holmes, 1998). Attending to how such matters may shape what a child says in an interview situation is of more value than treating such issues as mere 'nuisance variables' to be 'analysed out'. 


\section{The interview process}

There are many advantages of interviewing as a research method with children, especially preschool children who are unable to read or write (see Box 1). The focus of this article is on interviewing individual children. The special techniques of group interviewing have been described by Lewis (1992).

\section{Box 1 The advantages and disadvantages of interviewing as a method of research- ing children}

\section{Advantages}

- The flexibility and breadth of coverage made possible by the interview method can lead to in-depth exploration of and insights into the child's world

- The child can play a large part in determining the agenda

- The child does not need to be able to read and write

- Questions can be clarified if they are not understood

\section{Disadvantages}

- The process is time-consuming and therefore expensive

- Special training is advantageous, especially for researchers with little direct experience of communicating with children, yet training is rarely available and most researchers end up 'learning as they go' - this can have a marked effect on data quality

Interviewing can be combined with other means of data collection, such as child- and parent-rated questionnaires, as illustrated in the study by Kovacs et al. (1992) of children's non-compliance with medical treatment for insulin-dependent diabetes mellitus. Informal interviewing usually accompanies participant observation (Fine and Sandstrom, 1988), as in Holmes' (1991) study of kindergarten children's categories of play.
The main phases of the interview process are described below, preceded by some important ethical considerations.

\section{Some ethical issues to consider during pre- interview preparation}

Several ethical considerations relating to the interviewing of children are described here, taking into account key issues such as:

- children's cognitive competence to make decisions about their personal welfare and interests;

- children's rights of autonomy and self-determination;

- children's rights to privacy, confidentiality, consent and fair treatment.

In reality, children are generally perceived as having varying degrees of cognitive competence and limited autonomy (Burns and Grove, 1993), and are often denied the total freedom due to them to make choices or to exercise control over decisions that directly concern them.

Two major factors which often override the decision to take cognizance of the child's personal wishes are the perceived rights and protected obligation of parents, together with the expectation that society will act responsibly in safeguarding the child's best interests. However, many researchers question the assumption that parents always act in the child's best interests (Fletcher et al., 1995). Similarly, assumptions about society's responsibility for safeguarding the best interests of children can be questioned. Graue and Walsh (1998) note that in research with children, children are the knowledge holders, the permission granters and the rule setters - for adults.'

However, it is easy to envisage circumstances in which a conflict of interests could arise between the wishes of adults and children, with adults generally gaining the upper hand.

\section{Cognitive competence and consent}

The concept of cognitive maturity - that is, the point at which a child is considered to be capable of giving personal consent - remains controversial. The ambiguity that surrounds the transition from childhood to adulthood creates difficulties in determining when a child can be legally and ethically involved in decisions which require personal consent. Admittedly, statutory and legal definitions 
regarding childhood and adulthood are in place (Burns and Grove, 1993). However, the variations in the legal age of consent (from 16 to 18 years) from one context to another clearly indicate the uncertainty about this developmental phenomenon. In reality, there are no clearly defined indicators at any given age to confirm that a child is now ready to take personal responsibility for and control over his or her own welfare. However, both Burns and Grove (1993) and Graue and Walsh (1998) maintain that in matters concerning decisions about their welfare and interest, the personal consent of children should be sought whenever possible.

\section{Beneficence vs. autonomy}

While the principle of beneficence is concerned with ensuring that research subjects are protected from harm, respect for autonomy requires that subjects should be able to maintain control and make personal decisions. For example, in situations where the parents believe that talking to an expert (the researcher) might have therapeutic benefits for their child, they might persuade or even coerce the child into participating. This is clearly an infringement of the child's rights. The converse situation is that a child might willingly assent to participate in a research interview, while the parents might refuse to give their permission as a protective gesture, or because of guilt or embarrassment associated with the nature of the topic under investigation, especially if there is any implication of poor parenting.

Ethical considerations in relation to children can be complex, and the reader is referred to seminal works in this field, such as Alderson $(1993,1995)$, Gillon (1991), Grodin and Glantz (1994), Greig and Taylor (1999) and Stanley and Sieber (1992).

\section{During the interview}

Issues that relate to establishing and maintaining rapport, asking questions and responding to the child's emotions are reviewed in this section.

\section{Establishing and maintaining rapport}

When children feel respected, accepted and safe in any interview situation, they respond more freely and honestly than when they sense disapproval:

Mother of Jennifer (aged 9 years): Jennifer didn't like her [family doctor] and I felt we got off on the wrong foot. I felt Jennifer wasn't at ease with her. Jennifer wouldn't speak to her ... you've got to get on with kids, relate to them, or they clam up.

Despite the inherent power imbalance between children and researchers, many researchers highlight the potential for the child to set the agenda (Pellegrini, 1996; Graue and Walsh, 1998; Mandell, 1998). Morison (1996) describes how one 8year-old did this during a particularly memorable encounter, emptying his school-bag and proceeding to recount a story that he had written and to recite an Easter hymn that he was learning, before agreeing to talk with the researcher about what it was like to wet the bed. The message was clear: 'Let's look at what I can do well, then perhaps I'll talk to you about something that is a bit of a problem for me just now.'

Establishing and maintaining rapport is particularly important when the research topic is a sensitive one. Gentle coaxing and 'what if' questions can encourage self-disclosure:

Moya (researcher): Do any of your friends know about it [the bed wetting]?

(John shakes his head) ... (long pause) ...

How do you think they would feel if they did know?

John (aged 8 years): Well, there's one of my pals that knows, that's my really really best friend and he's not opened his mouth ...

Moya: Do you ever talk about it?

John: ... I says to him once, 'How would you feel if you wet the bed?' and he said he would feel the same as what I feel.

The child's relationship with the interviewer is one of the most important determinants of the child's openness, and of their 'communication competence' (Boggs and Eyberg, 1990). The manner adopted by the researcher during the interview is therefore particularly important (see Box 2).

At the outset of the interview it is important to establish its purpose, and with older children a time frame. Interviews of duration more than 30 minutes are likely to tax the child's powers of concentration (Faux et al., 1988). Serial interviewing can be a much more successful means of collecting in-depth data, with the added benefit that the researcher can analyse the first interview transcript and identify themes before meeting the young person again. 


\section{Box 2 Some general advice on the manner to adopt during interviews with children}

- Sit beside the child, where he or she chooses - this may be on the floor, on a sofa, or at a table

- Be attentive - be an active listener and show your interest in what the young person is saying

- Be observant of non-verbal clues - these include facial expression, eye contact, posture and distancing. Understanding and being responsive to a child's emotions can help to establish rapport, foster trust and prevent avoidable distress. It can also help the researcher to be sensitive to central issues, from the child's perspective, which can be explored through gentle probing

- Be imaginative - in the use of aids to communication, such as the use of 'faces feeling' cards, photographs and toys

- Do not try to hurry the interview - the success of the interview may be compromised if the young person feels under pressure

- Personalize the process - use the young person's name and the names of other family members, but not too often

- Use humour with discretion - it can easily be misunderstood. Avoid sarcasm, teasing and facetiousness with young people of any age, as it can be threatening to their selfesteem

- Avoid an interrogative or hectoring style gently probe when issues are sensitive, and be prepared to change the line of questioning at once if the young person is clearly upset by the direction that the interview is taking

- Avoid being judgemental - avoid criticizing others. The young person may pick up on your cues and simply reflect them back

- Ensure that your body language and verbal language are consistent with one another
This is also the time to establish the ground rules for the conversation, such as: 'If I ask you a question and you don't want to tell me the answer, that's OK.'

Children should also be informed that 'I don't know', 'I don't understand', and 'I don't remember' are also acceptable and legitimate answers (Warren et al., 1996), as this can reduce the likelihood of the child contriving an answer from fear of disappointing the researcher by giving a response that suggests uncertainty. Time taken over these preliminaries is usually time very well spent, and can form a firm foundation for the key task of asking questions relating to the research topic itself.

\section{Asking questions}

The influence of the child's linguistic development on the nature and outcomes of any interview has been discussed in relation to the attributes that the child brings to the interview (see Figure 1). Some general principles to consider when constructing questions for children are summarized in Box 3, based on this knowledge. Piloting questions and practising strategies for seeking clarification with the children of friends and colleagues can be a useful form of training for researchers who have limited experience of communicating with children. However, there is evidence that even when practice interviews are recommended, they are not always carried out (Warren et al., 1996), many researchers preferring to 'learn on the job'.

The interviewer's role in continuously monitoring the success of the communication process cannot be overstated, and it requires both skill and sensitivity. One of the commonest problems to be encountered is the young person who is clearly reluctant to hold a conversation. With experience, the empathetic researcher learns to distinguish between a number of causes of non-communicativeness. Some actions that can be taken in these circumstances are summarized in Table 3.

The underlying principle should be one of beneficence. Children are very adept at distinguishing between true benevolence and egoistic altruism. A genuine concern for the child's well-being should always be the guiding principle, which will usually bring in its wake high-quality, meaningful and detailed data. 


\section{Box 3 Some general principles when constructing questions for children during an informal interview}

- Only use vocabulary with which the child is familiar - if possible, find out from a parent the special words that the child uses for key objects or experiences before the interview with the child

- Attempt to gauge the child's stage of linguistic and social development from the earliest interactions (when establishing rapport)

- Keep questions short

- Only include one idea in each question

- Avoid complex grammatical constructions

- Match question content to the child's knowledge and experience

- Avoid abstract concepts - where possible and appropriate focus on concrete facts and recent events

- Avoid judgemental words such as 'good', 'bad', 'right', 'wrong' and 'fault'

- Avoid leading questions

- Be aware that pre-school children may have considerable difficulty with general open-ended questions (e.g. 'Tell me about ...')

\section{Responding to the child's answers}

The way in which a researcher responds to the child's attempts to reply to questions can be pivotally important in maintaining rapport and sustaining the young person's co-operation. The techniques involved are very similar to those employed in any therapeutic communication and include verbal and non-verbal acknowledgement, restating, seeking clarification and summarizing. The judicious use of praise, such as: 'You have explained that well' is a form of acknowledgement that can be positively reinforcing and which moves beyond the non-committal 'Ah-ha' or nod of the head, which can be used to indicate to the child that they have your full attention, and to encourage them to continue to talk. More subtle social cues are less effective with pre-school children. Critical statements should be avoided, as these are likely to be interpreted as disapproval.

\section{Responding to the child's emotions}

Whenever possible, it is advisable to structure any child interview by beginning with those topics that are least likely to be distressing, only moving to more sensitive topics once the child feels safe and comfortable with the researcher. Nevertheless, even the most experienced interviewers can inadvertently cause a child distress. The child's feelings should be acknowledged as legitimate before the researcher retreats to safer ground, such as a discussion of the family pets, favourite toys or particular achievements. The researcher should be prepared to abandon their own research goals if this is clearly the child's wish. It may be possible to retrieve these at a later visit, if the child and his or her family are happy with this strategy. At the time of seeking ethical approval for the research, it is important to clarify the support strategies that will be put in place to deal with possible post-interview concern or distress.

Kleinman and Copp (1993) encourage researchers to reflect upon their own emotions when in the field, as well as attempting to reflect the participant's emotions in transcript data and fieldnotes.

\section{After the interview}

After the interview it is important to express appreciation of the young person's co-operation. Verbal thanks are usually enough, but younger children may appreciate a small token of gratitude, such as a colouring book or pens. When interviewing street children in a city in Brazil, Gunther (1992) gave the children the equivalent of the money that they might have received from running errands during the time that it took to complete the interview.

The end of the interview is a good time to deal with any concerns that the child or their family may have, and to encourage them to re-establish contact with a member of the primary health care team if a health-related problem has been identified. This is also the time to negotiate with the child and the family any follow-up that is planned, and to inform them of the projected timetable for the research. 
Table 3 Some reasons why the young person may be reluctant to engage in the interview process

\begin{tabular}{|c|c|}
\hline Possible reason & Suggested action on the part of the interviewer \\
\hline $\begin{array}{l}\text { The young person is reluctant to talk } \\
\text { in the presence of a parent or } \\
\text { other family member }\end{array}$ & $\begin{array}{l}\text { Negotiate with the family an opportunity to talk with the young person } \\
\text { alone, and use this time to explore potentially sensitive issues. }\end{array}$ \\
\hline $\begin{array}{l}\text { The young person has been coerced } \\
\text { into attending }\end{array}$ & $\begin{array}{l}\text { Clarify with the young person any feelings they may have about } \\
\text { participating. Review the purpose and objectives of the study. Reassure } \\
\text { them about confidentiality. Be prepared to terminate the interview with } \\
\text { good grace, if this is clearly the young person's wish. }\end{array}$ \\
\hline $\begin{array}{l}\text { The young person feels } \\
\text { embarrassed or ashamed }\end{array}$ & $\begin{array}{l}\text { Empathy is the key. Taking time out to discuss safe issues can help to } \\
\text { establish a trusting relationship. It may help if the interviewer is a } \\
\text { nurse, and the line of enquiry is seen as a legitimate concern and the } \\
\text { interviewer is perceived as benevolent and non-judgemental. } \\
\text { Acknowledging the young person's embarrassment as 'OK', } \\
\text { understandable and not unusual in the circumstances can also help to } \\
\text { reduce the threat to the young person's self esteem. }\end{array}$ \\
\hline $\begin{array}{l}\text { The young person is intimidated, shy } \\
\text { or unaccustomed to talking } \\
\text { with an adult }\end{array}$ & $\begin{array}{l}\text { Again empathy is the key (see above). Establishing a trusting relationship } \\
\text { through the exploration of 'safe' issues can help to break the ice and } \\
\text { maintain communication. }\end{array}$ \\
\hline $\begin{array}{l}\text { The young person is unable to } \\
\text { express feelings in words }\end{array}$ & $\begin{array}{l}\text { Consider the use of other means of communication, including the use of } \\
\text { faces to express feelings, and drawing and the use of models. }\end{array}$ \\
\hline There are cultural barriers & $\begin{array}{l}\text { It may be necessary to involve a second interviewer who has greater } \\
\text { understanding and experience of the cultural norms to which the young } \\
\text { person is accustomed. }\end{array}$ \\
\hline
\end{tabular}

\section{The challenges of interviewing children with special needs}

Children with special needs, such as learning difficulties, or those who have been physically or sexually abused, can present particular challenges to the researcher that go beyond the scope of this article. Some useful references that review the practicalities of interviewing children in special circumstances are listed in Table 4. Specialist training is imperative, especially for those who do not have extensive clinical or personal experience of working in these areas.

\section{Interpreting and evaluating data: making sense of what young people say}

It may seem entirely reasonable to assume that, having been a child once, the researcher can to some extent adopt the mentality of having 'been there and done that', but this is a dangerous assumption because it treats childhood as if it were

Table 4 Interviewing children with special needs: some sources of reference

\begin{tabular}{ll}
\hline Children with special needs & Some sources of reference \\
\hline $\begin{array}{l}\text { Children who have been physically } \\
\text { or sexually abused } \\
\begin{array}{l}\text { Children with emotional and } \\
\text { behavioural disorders }\end{array}\end{array}$ & $\begin{array}{c}\text { American Academy of Child and Adolescent Psychiatry, 1997; Davies et } \\
\text { al., 1996; Lamb, 1994; Saywitz et al., 1996; Tully and Fritzon, 1996 }\end{array}$ \\
$\begin{array}{l}\text { Children with learning difficulties } \\
\text { Children with visual impairments }\end{array}$ & Fisher, 1990; Jacobsen et al., 1994; McConaughy and Achenbach, 1996 \\
\hline
\end{tabular}


some kind of enduring state (Rogers and Rogers, 1992). The axiom: 'that was then, this is now' is a useful reminder that researchers should beware of using their own childhood as some kind of touchstone.

The nature of the analytical methods employed should reflect the overall research approach adopted for a particular study, and should be consistent with the paradigmatic assumptions that underpin it (Silverman, 1985). It is therefore impossible to be prescriptive here. In essence, someone is talking to someone else, and matters of gender, age and ethnicity are all potentially relevant to what is said and how it is said. There is therefore a compelling argument that, at the very least, the interviewer's questions and the child's answers should be examined conjointly. To do otherwise, by simply focusing on the child's responses as a source of 'information', would be like watching only one player in a tennis match.

\section{Conclusion}

In this paper we have attempted to tease out some of the major methodological issues which arise when interviewing children for the purposes of research in primary care, and to point out their practical implications. From the review of the literature it is clear that the interview is a valuable research tool, and the insights gained can be an invaluable guide to action in contexts as diverse as helping young people with cystic fibrosis to deal with difficult peer situations (Christian and D'Auria, 1997) or the implementation of a secondary prevention strategy to minimize the impact of community violence on child witnesses (Rollins, 1997). The influence of the child's cognitive, linguistic and social development on the nature of the interaction has been explored. Paradoxically, although we were once children, our own cognitive, linguistic and social development means that we, as adults, are now aliens whenever we attempt to re-enter the territory of childhood. This raises the question of the extent to which adults can ever fully enter into a child's world.

\section{References}

Alderson, P. 1993: Children's consent to surgery. Buckingham: Open University Press.
Alderson, P. 1995: Listening to children: children, ethics and social research. Barkingstock: Barnardos.

Almquist, B. 1989: Age and gender differences in children's Christmas requests. Play and Culture 2, 2-19.

Amato, P.R. and Ochiltree, G. 1987: Interviewing children about their families: a note on data quality. Journal of Marriage and the Family 49, 669-75.

American Academy of Child and Adolescent Psychiatry 1997: Practice parameters for the forensic evaluation of children and adolescents who may have been physically or sexually abused. Journal of the American Academy of Child and Adolescent Psychiatry 36, 423-42.

Andrews, A. and Withey, W. 1976: cited in McDowell, I. and Newell, C. 1987: Measuring health: a guide to rating scales and questionnaires. Oxford: Oxford University Press.

Atuel, T. M., Williams, P. D. and Camar, M. T. 1988: Determinants of Filipino children's responses to the death of a sibling. Maternal Child Nursing Journal 17, 115-34.

Band, E. B. and Weisz, J. R. 1988: How to feel better when it feels bad: children's perspective on coping with everyday stress. Developmental Psychology 24, 247-53.

Banister, P., Burman, E., Parker, I., Taylor, M. and Tindall, C. 1994: Qualitative methodology in psychology: a research guide. Buckingham: Open University Press.

Barker, P. 1990: Clinical interviews with children and adolescents. New York: W. W. Norton.

Beoku-Betts, J. 1994: When black is not enough: doing field research among Gullah women. NWSA Journal 6, 413-33.

Blum, R.W. 1992: Chronic illness and disability in adolescence. Journal of Adolescent Health 13, 364-68.

Boggs, S. R. and Eyberg, S. 1990: Interview techniques and establishing rapport. In La Greca, A. M., editor. Through the eyes of the child: obtaining self-reports from children and adolescents. Boston, MA: Allyn and Bacon, 85-108.

Broderick, C. B. 1993: Understanding family process: basics of family systems theory. Newbury Park, CA: Sage.

Bronfenbrenner, U. 1986: Ecology of the family as a context for human development: research perspectives. Developmental Psychology 22, 723-42.

Broome, M. E. and Endsley, R. C. 1989: Maternal presence, child-rearing practices, and children's response to an injection. Research in Nursing and Health 12, 229-35.

Bruner, J. 1985: Vygotsky: a historical and conceptual perspective. In Wertsch, J. V., editor. Culture, communication and cognition: Vygotskian perspectives. Cambridge: Cambridge University Press, 21-34.

Burns, N. and Grove, S. K. 1993: The practice of nursing research: conduct critique and utilization, 2nd edn. London: W. B. Saunders.

Carter, C. A., Bottoms, B. L. and Levine, M. 1996: Linguistic and socioemotional influences on the accuracy of children's reports. Law and Human Behaviour 20, 335-58.

Christian, B. J. and D'Auria, J. P. 1997: The child's eye: memoirs of growing up with cystic fibrosis. Journal of Pediatric Nursing: Nursing Care of Children and Families 12, 3-12. 
Cummings, E. A., Reid, G. J., Finley, G. A. and McGrath, P. J. 1996: Prevalence and source of pain in pediatric patients. Pain 68, 25-31.

Dahlquist, L. M. 1990: Obtaining child reports in health care settings. In La Greca, A. M., editor. Through the eyes of the child: obtaining self-reports from children and adolescents. Boston, MA: Allyn and Bacon, 345-439.

Davies, D., Cole, J., Albertella, G., McCulloch, L., Allen, K. and Kekevian, H. 1996: A model for conducting forensic interviews with child victims of abuse. Child Maltreatment 1, 189-99.

De Loache, J. S. 1995: The use of dolls in interviewing young children. In Zaragoza, M. S. et al., editors. Memory and testimony in the child witness. Thousand Oaks, CA: Sage, 160-78.

Dent, H. R. 1991: Experimental studies of interviewing child witnesses. In Doris, J., editor. The suggestibility of children's recollections. Washington, DC: American Psychological Association, $138-46$.

Department of Health 1997: The new NHS: modern, dependable. London: The Stationery Office.

Department of Health 1998: A first-class service: quality in the new NHS. London: Department of Health.

Department of Health 1999a: Making a difference: strengthening the nursing, midwifery and health visiting contribution to health and healthcare. London: Department of Health.

Department of Health 1999b: Patient and public involvement in the new NHS. London: Department of Health.

Eiser, C. 1993: Growing up with a chronic disease: the impact on children and their families. London: Jessica Kingsley.

Enelow, A. J., Forde, D. L. and Brummel-Smith, K. 1996: Interviewing and patient care, 4th edn. New York: Oxford University Press.

Faller, K. and Everson, M. 1996: Introduction to child interviewing. Part 2. Child Maltreatment 1, 187-88.

Faux, S. A., Walsh, M. and Deatrick, J. A. 1988: Intensive interviewing with children and adolescents. Western Journal of Nursing Research 10, 180-94.

Fine, G. A. and Sandstrom, K. L. 1988: Knowing children: participant observation with minors. Qualitative Research Methods Series 15. Newbury Park, CA: Sage.

Fisher, G. 1990: Interviewing mentally retarded children. In Barker, P., editor. Clinical interviews with children and adolescents. New York: W. W. Norton, 88-104.

Fletcher, N., Holt, J., Brazier, M. and Harris, J. 1995: Ethics, law and nursing. Manchester: Manchester University Press.

Gallo, A. M., Breitmayer, B. J., Knafl, K. A. and Zoeller, L. H. 1991: Stigma in childhood chronic illness: a well sibling perspective. Paediatric Nursing 17, 21-25.

Gillon, R. 1991: Research on the vulnerable: an ethical overview. In Gillon, R., editor. Protecting the vulnerable: autonomy and consent in health care. London: Routledge, 52-76.

Goodwin, M. H. 1997: Children's linguistic and social worlds. Anthropology Newsletter (American Anthropological Association) 38, 1-5.

Graue, M. E. and Walsh, D. J. 1998: Studying children in context: theories, methods and ethics. Thousand Oaks, CA: Sage.
Greenstock, J. and Pipe, M. 1996: Interviewing children about past events: the influence of peer support and misleading questions. Child Abuse and Neglect 20, 69-80.

Greig, A. and Taylor, J. 1999: Doing research with children. London: Sage.

Grodin, M. A. and Glantz, L. E. 1994: Children as research subjects: science, ethics and the law. New York: Oxford University Press.

Gunther, H. 1992: Interviewing street children in a Brazilian city. Journal of Social Psychology 132, 359-67.

Hetherington, E. M. and Parke, R. D. 1998: Child psychology: a contemporary viewpoint, 5th edn. Boston, MA: McGrawHill College.

Heusel, K. J. 1990: The experience of homelessness viewed through the eyes of homeless school-age children. $\mathrm{PhD}$ Thesis, Ohio State University, $\mathrm{OH}$.

Holmes, R. 1991: Categories of play: a kindergarten's view. Play and Culture 4, 43-50.

Holmes, R. 1998: Field work with children. Thousand Oaks, CA: Sage.

Hughes, J. N. 1989: The child interview. School Psychology Review 18, 247-59.

Hughes, J. N. and Baker, D. B. 1990: The clinical child interview. New York: Guildford Press.

Huntington, G. 1987: Different apron strings: children as field assistants. Human Organization 46, 83-85.

Huon, G.F., Godden, V. M. and Brown, L. B. 1997: Reports of dieting among children: effects of interview style and approach to information collection. British Journal of Clinical Psychology 36, 33-40.

Hutcheson, G. D., Baxter, J. S., Telfer, K. and Warden, D. 1995: Child witness statement quality: question type and errors of omission. Law and Human Behaviour 19, 631-48.

Inglis, J. 1989: Health interviews for school children. Midwife Health Visitor and Community Nurse 25, 202-4.

Jacobsen, L. K., Rabinowitz, I., Popper, M. S. and Solomon, R. J. 1994: Interviewing prepubertal children about suicidal ideation and behavior. Journal of the American Academy of Child and Adolescent Psychiatry 33, 439-52.

Kanfer, R., Eyberg, S. M. and Krahn, G. L. 1992: Interviewing strategies in child assesment. In Walker, C. E. and Roberts, M. C., editors. Handbook of clinical psychology. New York: John Wiley, 49-62.

Kazak, A. E. 1992: Social context of coping with childhood chronic illness. In La Greca, A. M. et al., editors. Stress and coping in child health. New York: Guildford, 262-78.

Kleinman, S. and Copp, M. 1993: Emotions and fieldwork. Newbury Park, CA: Sage.

Kortesluoma, R. and Hentinen, M. 1995: Qualitative interview in a search for children's experiences. Hoitotiede 7, 119-27.

Kovacs, M., Goldston, D., Obrosky, D. S. and Iyengar, S. 1992: Prevalence and predictors of pervasive non-compliance with medical treatment among youths with insulin-dependent diabetes mellitus. Journal of the American Academy of Child and Adolescent Psychiatry 31, 1112-19.

Lamb, M. E. 1994: The investigation of child sexual abuse: an

Primary Health Care Research and Development 2000; 1: 113-130 
interdisciplinary consensus statement. Child Abuse and Neglect 18, 1021-28.

Lamb, M. E., Sternberg, K. J. and Esplin, P. W. 1994: Factors influencing the reliability and validity of statements made by young victims of sexual maltreatment. Journal of Applied Developmental Psychology 15, 255-80.

Lewin, L. 1995: Interviewing the young child sexual abuse victim. Journal of Psychosocial Nursing and Mental Health Services 33, 5-10.

Lewis, A. 1992: Group child interviews as a research tool. British Educational Research Journal 18, 413-21.

Lincoln, Y.S. and Guba, E. G. 1985: Naturalistic inquiry. Beverly Hills, CA: Sage.

Maccoby, E. 1990: Gender and relationships: a developmental account. American Psychologist 45, 513-20.

Macpherson, C. B. 1962: The political theory of possessive individualism. London: Oxford University Press.

Mandell, N. 1988: The least-adult role in studying children. Journal of Contemporary Ethnography 16, 433-67.

McConaughy, S. H. 1996: The interview process. In Breen, M. J. and Fiedler, C. R., editors. Behavioral approach to assessment of youths with emotional/behavioral disorders: a handbook for school-based practitioners. Austin, TX: Pro-ed, 181-223.

McConaughy, S. H. and Achenbach, T. M. 1996: Contributions of a child interview to multimethod assessment of children with EBD (emotional and behavioural disorders) and LD (learning disabilities). School Psychology Review 25, 24-39.

Meyer, D. 1992: Children's responses to nursing attire. Paediatric Nursing 18, 157-60.

Minkes, J., Robinson, C. and Weston, C. 1994: Consulting the children: interviews with children using residential respite care services. Disability and Society 9, 47-57.

Moir, J. and Abraham, S. C. S. 1996: Why I want to be a psychiatric nurse: constructing an identity through contrasts with general nursing. Journal of Advanced Nursing 23, 295-98.

Mordock, J. B. 1996: Treatment of sexually abused children: interview technique, disclosure, and progress in therapy. Journal of Child Sexual Abuse 5, 105-21.

Morison, M. J. 1996: Family perspectives on bed-wetting in young people. Aldershot: Avebury.

Moser, C. A. 1958: cited in Oakley, A. 1981: Interviewing women: a contradiction in terms. In Roberts, H., editor. Doing feminist research. London: Routledge and Kegan Paul, 30-61.

Moston, S. 1990: How children interpret and respond to questions: situational sources of suggestibility in eye-witness interviews. Social Behaviour 5, 155-67.

Mussen, P. H., Conger, J. J., Kagan, J. and Huston, A. C. 1990: Child development and personality, 7th edn. New York: Harper and Row.

Mussen, P. H., Conger, J. J., Kagan, J. and Huston, A. C. 1996: Child development and personality, 8th edn. New York: Harper and Row.

Nelson, K. 1992: Emergence of autobiographical memory at age 4. Human Development 35, 172-77.

Oakley, A. 1981: Interviewing women: a contradiction in terms.
In Roberts, H., editor. Doing feminist research. London: Routledge and Kegan Paul, 30-61.

Oakley, A. 1994: Women and children first and last: parallels and differences between children's and women's studies. In Mayall, B., editor. Children's childhoods: observed and experienced. London: Falmer, 13-32.

Pellegrini, A. 1996: Observing children in their natural worlds: a methodological primer. Maywah, NJ: Lawrence Erlbaum.

Priestley, G. and Pipe, M. E. 1997: Using toys and models in interviews with young children. Applied Cognitive Psychology 11, 69-87.

Pynoos, R. S. and Eth, S. 1988: Witness to violence: the children interview. In Chess, S. et al., editors. Annual progress in child psychiatry and child development. New York: Brunner Mazel, 299-326.

Robinson, C. A. 1987: Preschool children's conceptualizations of health and illness. Children's Health Care 16, 89-96.

Rogers, R. S. and Rogers, W.S. 1992: Stories of childhood. Toronto: University of Toronto Press.

Rollins, J. A. 1997: Minimizing the impact of community violence on child witnesses. Critical Care Nursing Clinics of North America 9, 211-20.

Rosenblatt, P. C. 1994: Metaphors of family systems theory: toward new constructions. New York: Guildford Press.

Saywitz, K. J. and Goodman, G. S. 1996: Interviewing children in and out of court: current research and practice implications. In Briere, J. et al., editors. The APSAC handbook on child maltreatment. Thousand Oaks, CA: Sage, 297-318.

Saywitz, K. J., Snyder, L. and Lamphear, V. 1996: Helping children tell what happened: a follow-up study of the narrative elaboration procedure. Child Maltreatment 1, 200-12.

Schetky, D.. 1997: Child victims in the legal system. In Appelbaum, P. S. et al., editors. Trauma and memory: clinical and legal controversies. New York: Oxford University Press, 496-507.

Scott-Jones, D. 1994: Ethical issues in reporting and referring in research with low-income minority children. Ethics and Behaviour 4, 97-108.

Shapiro, J. 1991: Interviewing children about psychological issues associated with sexual abuse. Psychotherapy 28, 55-66.

Shotter, J. 1985: Social accountability and self-specification. In Gergen, K. J. and Davies, K. E., editors. The social construction of the person. New York: Springer-Verlag, 167-89.

Shotter, J. 1989: Social accountability and the social construction of 'you'. In Gergen, K. J. and Shotter, J., editors. Texts of identity. London: Sage, 133-51.

Silverman, D. 1985: Qualitative methodology and sociology: describing the social world. Aldershot: Gower.

Silverman, W. K. 1994: Structured diagnostic interviews. In Ollendick, T. H. et al., editors. International handbook of phobic and anxiety disorders in children and adolescents: issues in clinical child psychology. New York: Plenum Press, 496-506.

Stanley, B. and Sieber, J. E. 1992: Social research on children and adolescents: ethical issues. Newbury Park, CA: Sage.

Steward, M., Bussey, K., Goodman, G. and Saywitz, K. 1993: 
Implications of developmental research for interviewing children. Child Abuse and Neglect 17, 25-37.

Stone, W. L. and Lemanek, K. L. 1990: Development issues in children's self-reports. In La Greca, A. M., editor. Through the eyes of the child: obtaining self-reports from children and adolescents. Boston, MA: Allyn and Bacon, 18-55.

Tully, B. and Fritzon, K. 1996: Resource manual of specialised investigative interviewing: obtaining testimony from children and psychologically vulnerable adults who are suspected of being perpetrators or victims of crime or abuse. London: Law Group.

Vygotsky, L. 1962: Thought and language. Cambridge, MA: MIT Press \& John Wiley.

Warren, A. R. and McGough, L. S. 1996: Research on children's suggestibility: implications for the investigative interview. Criminial Justice and Behavior 23, 269-303.
Warren, A. R., Woodall, C. E., Hunt, J. S. and Perry, N. W. 1996: It sounds good in theory, but ... do investigative interviews follow guidelines based on memory research? Child Maltreatment 1, 231-45.

Wescott, H. 1994: On sensitivity and ethical issues in child witness research. Child Abuse and Neglect 18, 287-90 (letter).

Wetherell, M. and Maybin, J. 1996: The distributed self: a social constructionist perspective. In Stevens, R., editor. Understanding the self. London: Sage, 219-79.

Williams, C. and Heikes, E. 1993: The importance of researcher's gender in the in-depth interview: evidence from two case studies of male nurses. Gender and Society 7, 280-91.

Woodgate, R. and Kristjanson, L. J. 1996: 'My hurts': hospitalized young children's perceptions of acute pain. Qualitative Health Research 6, 184-201. 